\title{
Life cycle assessment of butanol production
}

\author{
Marta Brito, Florinda Martins ${ }^{\Uparrow}$ \\ REQUIMTE/ISEP, Rua Dr. António Bernardino de Almeida, 431, 4200-072 Porto, Portugal
}

\begin{abstract}
The goal of this work was to analyse and compare the environmental impacts of three production meth- ods of butanol. The first one is based on the oxo synthesis and the others use ABE (acetone, butanol and ethanol) fermentation. A life cycle assessment for all alternatives under study was carried out. The ABE fermentation using corn as substrate presents the highest environmental impact and the ABE fermenta- tion using wheat straw is the one that presents the lowest environmental impact, when the allocation method was based on mass. Considering an economic allocation method, the relative weight of butanol raised which increased considerably the environmental impact value in ABE processes due to the lower economic value of gases.

A sensitivity analysis was performed for the production of butanol from the two ABE processes varying the data of lower quality to analyse how this would affect the environmental impacts. In the ABE process with wheat straw the variations performed within the scope of the sensibility analysis had no meaningful effect in the global impact $(<4.0 \%)$ except when the production of gases was varied. In this case the reduc- tion of $50 \%$ in the mass of gases produced could result in an increase of roughly $40 \%$ in the global impact. For the ABE process with the corn the variation of wastewater produced resulted in a decrease of global environmental impact lower than $1 \%$.
\end{abstract}

\section{Keywords:}

ABE

Butanol LCA

Biofuels Sustainability

\section{Introduction}

Nowadays energy is an issue of great importance to countries' development. Security of supply and the instability of prices and markets together with increasing concerns related to environmental impacts due to the use of fossil fuels have led to new energy policies. Climate change and depletion of resources are major problems that must be tackled in the short period. These concerns led to the promotion of renewable energy sources and alternatives ways of producing energy and fuels. The Renewable Energy Directive [1] and the Energy/Climate package in European Union and the targets established are stirring research and are key drivers for a more sustainable energy system. The national targets established by each Member State to renewable energy can be achieved by a combination of the use of renewable energy sources to produce electricity, heat/cooling and transportation [2]. International commitments such as the Kyoto Protocol reinforced the role of renewables and studies show that the EU should keep on increasing the share of renewable energy for lowering emission levels of $\mathrm{CO}_{2}$ [3]. Renewable energy innovations are very important in energy sector and several studies have been conducted to determine the major

\footnotetext{
$\Uparrow$ Corresponding author.

E-mail address: ffm@isep.ipp.pt (F. Martins).
}

factors that influenced it [4]. These environment and energy concerns are shared worldwide since many environmental problems can only be solved if considered globally and trade/market conditions are increasingly global questions. Recent studies have analysed the relation between $\mathrm{CO}_{2}$ emissions and other variables such as real output, energy consumption, trade, etc. for several countries [5-9]. In many of the those studies the application of the environmental Kuznets curve (EKC) is verified [5-7,10,11]. Some authors give special attention to the relation between renewable and non-renewable energy sources and $\mathrm{CO}_{2}$ emissions [10,11]. Energy consumption is very important for $\mathrm{CO}_{2}$ emissions and conclusions emphasised the need for the implementation of energy efficiency policies $[6,7]$ and the increase in investment for further development of renewable technology $[9,11]$. In addition it is recommended an increase in energy consumption from renewable sources [8-11].

In this scenario biofuels, including n-butanol, are presented as alternatives worthwhile exploring and developing, since they can be an ecological and economical option. Butanol is an alcohol with a 4-carbon structure and the chemical formula is $\mathrm{C}_{4} \mathrm{H}_{10} \mathrm{O}$ and has four isomers namely n-butanol, 2-butanol, iso-butanol and tertbutanol $[12,13]$. This alcohol can be produce from biomass by fermentation (biobutanol) or from fossil fuels obtaining the similar 
chemical properties $[14,15]$. $\mathrm{N}$-butanol has been pointed out as a substitute for gasoline [13].

The most currently used process for the production of $n$-butanol is the chemical production from petroleum sources especially by oxo synthesis $[12,14]$. However the formation of butanol in the microbial fermentation was first reported in 1861 [16], and through out the years the methods used for producing it changed due to science developments and economic reasons. In fact it started to be industrially produced, during World Wars I and II, using the $A B E$ (acetone, butanol and ethanol) fermentation, using as substrates corn and molasses $[17,18]$. This solvent was made with a variety of substrates all over the world such as in United States of America, United Kingdom, China, Russia, South Africa and India. During the World War II this alcohol was produced with Clostridium acetobutylicum bacteria because it was cheaper to produce by this way in comparison with petrochemicals [18].

In the 50's, the butanol production decreased due to the increase of molasses' price and processes reliability problems and for those reasons the $A B E$ fermentation with substrates was replaced by petrochemical process in the 80's [12,17].

In the 90's, the prices of the oil barrels increased through out the years and this raised the interest in other products and production methods. Some investigators started to improve the ABE fermentation with the implementation of new genetic engineering techniques, incorporation of more productive reactors and news methods to recover the solvent [12]. Different strains of bacteria were used and especially Clostridium beijerinckii BA101 presented high efficiency starch conversion into acetone and butanol [19]. Nowadays the interest for the butanol production increased again due to promotion of the use of renewable energy sources and the fact it can be used as fuel.

The oxo synthesis is based on the hydroformylation of propene, followed by the hydrogenation of the formed aldehydes. Catalysts such as Co, Rh or Ru are used [20].

In the $A B E$ production method the following parameters should be considered:

\section{- Type of substrates}

Several types of substrate can be used, such as wheat straw, corn, sugarcane biomass, wastes from agriculture, molasses and other raw materials. Generally they can be classified in cellulosic (bagasse, wheat straw, corn stover, switchgrass) and noncellulosic (glucose, sugarcane, corn) materials. The choice of substrate involves technical, economic and even social reasons, because materials that do not compete with food supply are more sustainable. Other raw materials such as glycerol (a by-product of biodiesel production) and algae are also being studied [21-23].

\section{- Type of microorganisms}

There are a great number of microorganisms that can be used in this process such as Clostridium acetobutylicum, Clostridium aurantibutyricum, Clostridium beijerinckii, Clostridium butyricum, etc. [24]. However the most important ones in butanol production using $\mathrm{ABE}$ fermentation are Clostridium acetobutylicum and Clostridium beijerinckii since they are high butanol producers [25].

\section{- Fermentation processes}

Fermentation can be performed in three different ways, fedbatch, batch and continuous [26]. In batch fermentation the substrate and nutrients are placed in the reactor and the inoculate added. Fermentation is carried out at $35-37^{\circ} \mathrm{C}$ and after process is finished the solids are removed and the liquid can be sent to distillation. This process presents low productivities [27]. Fed-batch fermentation is used in processes where substrates can be toxic to microorganisms. Initially a small quantity of substrate is loaded to the reactor and more substrate is added during the process, always maintaining the substrate concentration below the toxic level. Usually the solvent is being extracted since butanol is toxic to bacteria. In this method the new recovery techniques are used allowing the simultaneous recovery of all products. In continuous fermentation the production can be optimized. The system can have a single stage or multiple. One of the main difficulties is the fluctuation in production levels [12].

\section{- Recovery processes}

The main downstream fermentation processes are liquid-liquid extraction, perstraction, pervaporation and gas stripping [24]. In the first process a solvent is added and since butanol is more soluble in the extractant it is removed. Then it can be recovered by back extraction or by distillation. Perstration also uses an extractant but there is no direct contact between the extractant and fermentation broth due to the existence of a membrane that allows diffusion of ABE. Pervaporation uses a selective membrane and there is a gaseous phase on the other side into which the volatiles are extracted. The volatiles are then condensed and recovered. In gas stripping nitrogen or the fermentation gases are continuously sparged into the reactor and the gases are channelled to a condenser. The volatile solvents are then recovered by cooling [24].

\section{- Inhibitory processes}

Inhibitory processes in $A B E$ fermentation are one of the main drawbacks, since it contributes to low productivities. The substrate can be toxic to microorganisms and the products of fermentation (acetone, butanol and ethanol) are also toxic for most clostridial cultures. Maximum concentration is around $20 \mathrm{~g} / \mathrm{L}$ which on the other hand imposes restrictions at the substrate level. A common solution to solve this problem is the continuous removal of solvents. Other solution concerns the development of new strains that present higher resistance. When lignocelluosic materials are used pretreatment and hydrolysis are necessary but that can originate other inhibitory components such as formic acid, acetic acid, levulinic acid, furfural, and hydroxymethyl furfural [28-30].

The economic viability of butanol production from ABE fermentation is highly affected by price of substrates, presence of inhibitors and inefficient recovery of products [28,31].

Life Cycle Assessment (LCA) evaluates the environmental impacts associated with a product or service throughout its life cycle, from extraction of raw materials to final disposal of waste. It analyzes the flow of materials and energy flow involved in all stages of the life cycle such as production, use and disposal. LCA is performed in four steps, according to norms ISO14040-44, namely goal and scope, inventory analysis, impact assessment and interpretation [32]. It has been used in the environmental analysis of biofuels [33]. In this work a life cycle assessment was carried out to analyse and compare the environmental impacts of three production methods of butanol. The first one is based on the oxo synthesis and the others use ABE (acetone, butanol and ethanol) fermentation.

\section{Production of butanol}

Three production processes were considered in this studied: the oxo synthesis and two ABE fermentation processes, one with wheat straw as substrate and the other one using corn. For the two $A B E$ fermentation processes data for inventory analysis were 
gathered from bibliography and some estimated considering similar processes.

\subsection{Butanol production using oxo process}

The oxo synthesis is based on the hydroformylation of propene. The feed streams are propene and $\mathrm{CO}+\mathrm{H}_{2}$ and a catalyst is used. This process is followed by the catalytic hydrogenation of the formed aldehydes. The hydroformylation process has several variations concerning reaction conditions (pressure, temperature) and catalyst used. Classic high pressure processes (used until the beginning of the 1970s) leads to about $75 \% 1$-butanol and about 25\% 2-methyl-1-propanol but recent processes operating with low pressures and using modified Rh-catalysts can achieve $95 \%$ of $n$-butanol and 5\% 2-methyl-1-propanol [34]. The main features of the oxo process are presented in Fig. 1.

\subsection{Butanol production from wheat straw using ABE process in batch reactor}

In this process wheat straw was used as the substrate. Wheat straw was first milled then treated with dilute sulphuric acid. The mixture was cooled and $\mathrm{pH}$ adjusted with a solution of sodium hydroxide. The next step was the hydrolysis of the mixture using enzymes. This was followed by cooling and $\mathrm{pH}$ adjusting with $\mathrm{NaOH}$ and fermentation with Clostridium beijerinckii P260. After fermentation solids were removed by centrifugation and products recovered by distillation. Butanol-water azeotrope broken by application of a hydrophilic pervaporation membrane. Ethanol would be dehydrated using a hydrophilic membrane [35]. Fig. 2 presents the main features of this process.

\subsection{Butanol production from corn using ABE process in batch reactor}

In this process corn was used as the substrate. Corn was soaked, followed by grinding, sieving, and centrifugation. The germ containing oil was removed by flotation after grinding. Sieving removed fibre and centrifugation removed the gluten. The nest step was fermentation with Clostridium beijerinckii BA101. Cell mass was removed by centrifugation and ABE by distillation [36]. Fig. 3 presents the main features of this process.

\section{Llife cycle analysis}

\subsection{Objective and scope of study}

The purpose of this work is to do a life cycle assessment for all the alternatives mentioned above. This study was based on data available in bibliography and secondary data given by proper LCI data sets available on Ecoinvent. The Ecoinvent database v. 3 provided data for the several processes. The methodology of impact assessment used was the "IMPACT 2002+". The methodology of impact assessment "IMPACT 2002+" proposes a feasible implementation of a midpoint in a combined approach to damage. It considers four categories of damage: human health, ecosystem quality, climate change, resources. This type of methodology was chosen for the analysis of environmental impacts for LCA of $n$ butanol production since it has the advantage of being express in points which facilitates the calculations. The LCA included all raw materials and butanol production (excluding fugitive emissions) and did not include the construction, distribution and use. The cooling water was assumed to have low impact, so it was also not considered and the solids were sent to anaerobic digestion (AD) to produce methane. Enzymes were also not considered since their amount is very small when considering the overall inputs and outputs of systems. The allocation of impacts was performed firstly based on the ratio of the masses of the products obtained and secondly based on the economic value of products. The data collected gathers the information about the flows of matter and energy throughout the production chain of $n$-butanol. The functional unit considered was $1 \mathrm{~kg}$ of $\mathrm{n}$-butanol.

\subsection{Inventory}

Figs. 4 and 5 show the materials/energy of the inventories for the production of $n$-butanol using the $A B E$ fermentation processes. Data were mainly directly collected from bibliography $[35,36]$ and only a small amount were estimated based on bibliography [3741]. The inventory was not made for oxo process since for this process the impact assessment was directly provided by Ecoinvent database v.3.

The mass ratios considered for allocation for the two processes are given in Table 1. Economic allocation considered the economic value of products and the ratios are also presented in Table 1.

Analyzing the values presented in Table 1 it is possible to conclude that when the allocation method is based on the economic value the weight of $n$-butanol significantly increases due to the low economic value of gases. For the process with wheat straw the corresponding percentage is more than the double of the value obtained for mass allocation. In the other process the weight of $n$ butanol also significantly increases but in this case is roughly 1.5 higher.

\subsection{Environmental impact assessment}

For the first process, the oxo process, impacts were directly retrieved from Ecoinvent database v. 3 and the total impact for the production of $1 \mathrm{~kg}$ of butanol is $1.05 \times 10^{-3}$ points. For the other two processes environmental impact assessment was calculated considering the inputs and outputs of the systems. Fig. 6 presents the impacts for $1 \mathrm{~kg}$ of butanol for oxo process for all damage categories and Fig. 7 presents the results for the two ABEprocesses, considering mass and economic allocation. For the oxo process the impacts are higher in damage categories climate change and resources and for $A B E$ process with wheat straw the same trend is verified. For the last alternative the processes that most contribute to environmental impact are the production of steam (69\%) and wheat straw (14\%). For ABE process with corn the impacts are higher in the other two damage categories namely ecosystem quality and human health as showed in Fig. 7. For alternative the processes that most contribute to environmental impact are the production of corn $(77 \%)$ and steam (18\%). The use of corn as substrate raises another problem related to sustainability, namely the use of food crops to produce energy [42]. Fig. 8 presents the total impact for both $A B E$ processes and allocations. From this figure it is possible to conclude that $A B E$ production with wheat straw using

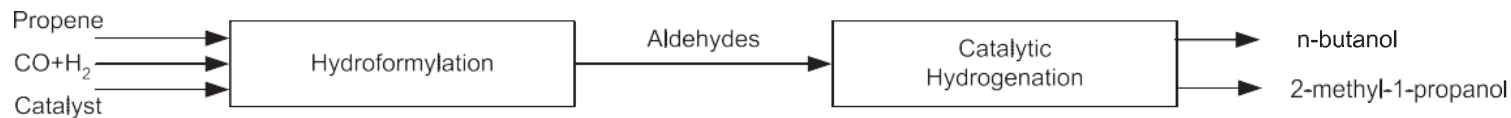




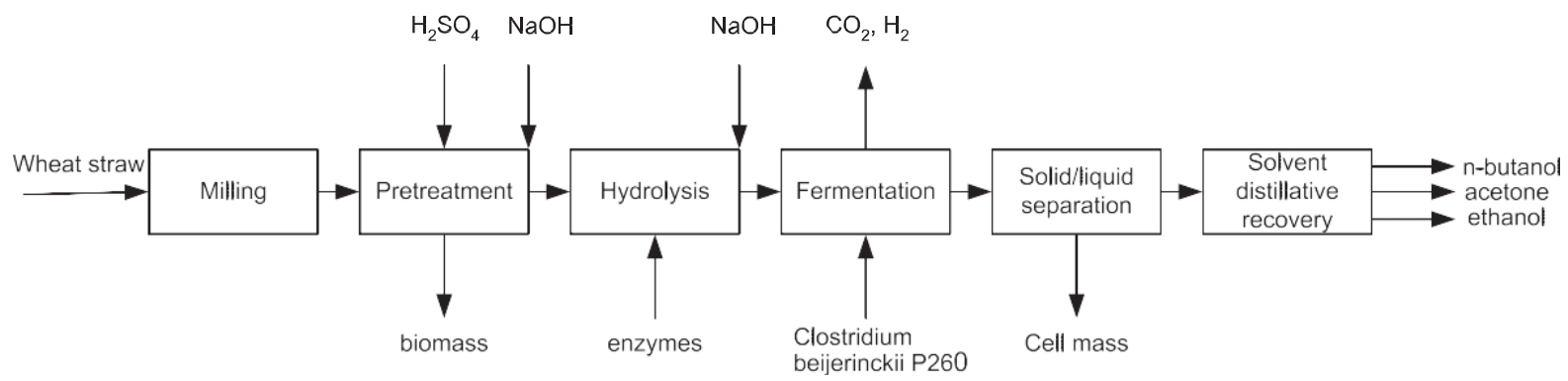

Fig. 2. Main features of $A B E$ process with wheat straw.

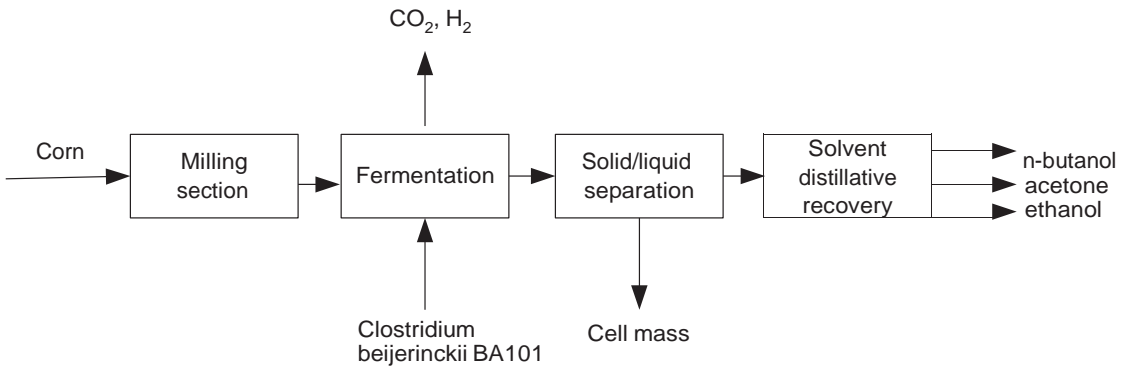

Fig. 3. Main features of ABE process with corn.

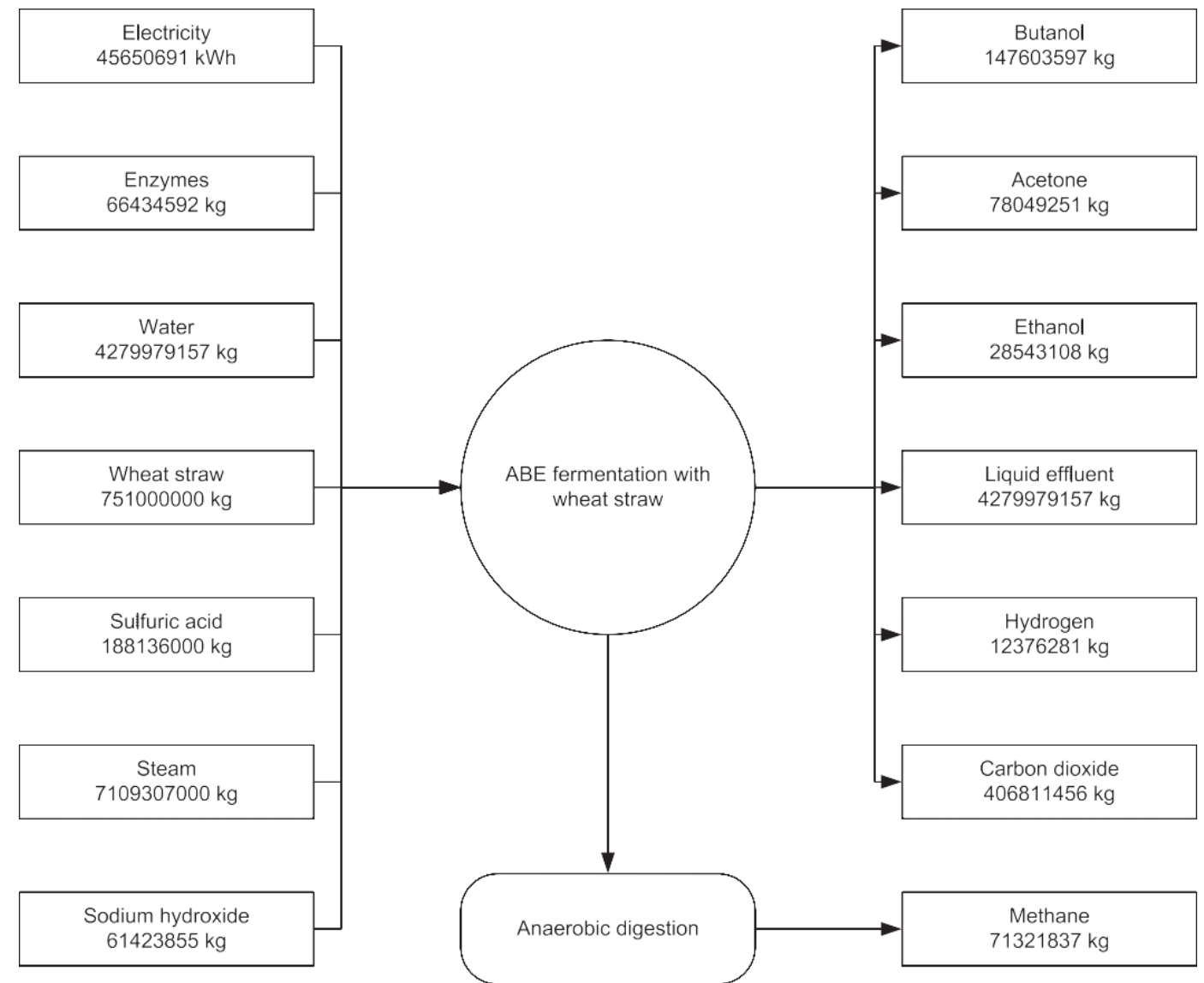

Fig. 4. Inventory ABE process with wheat straw.

mass allocation presents the lowest environmental impact of all processes followed by oxo process. However when economic allocation is considered the total environmental impact related to
$\mathrm{ABE}$ processes are much higher than the oxo process and the values obtained for both $A B E$ processes are very close. This is due to the low economic value of gases produced during fermentation. 


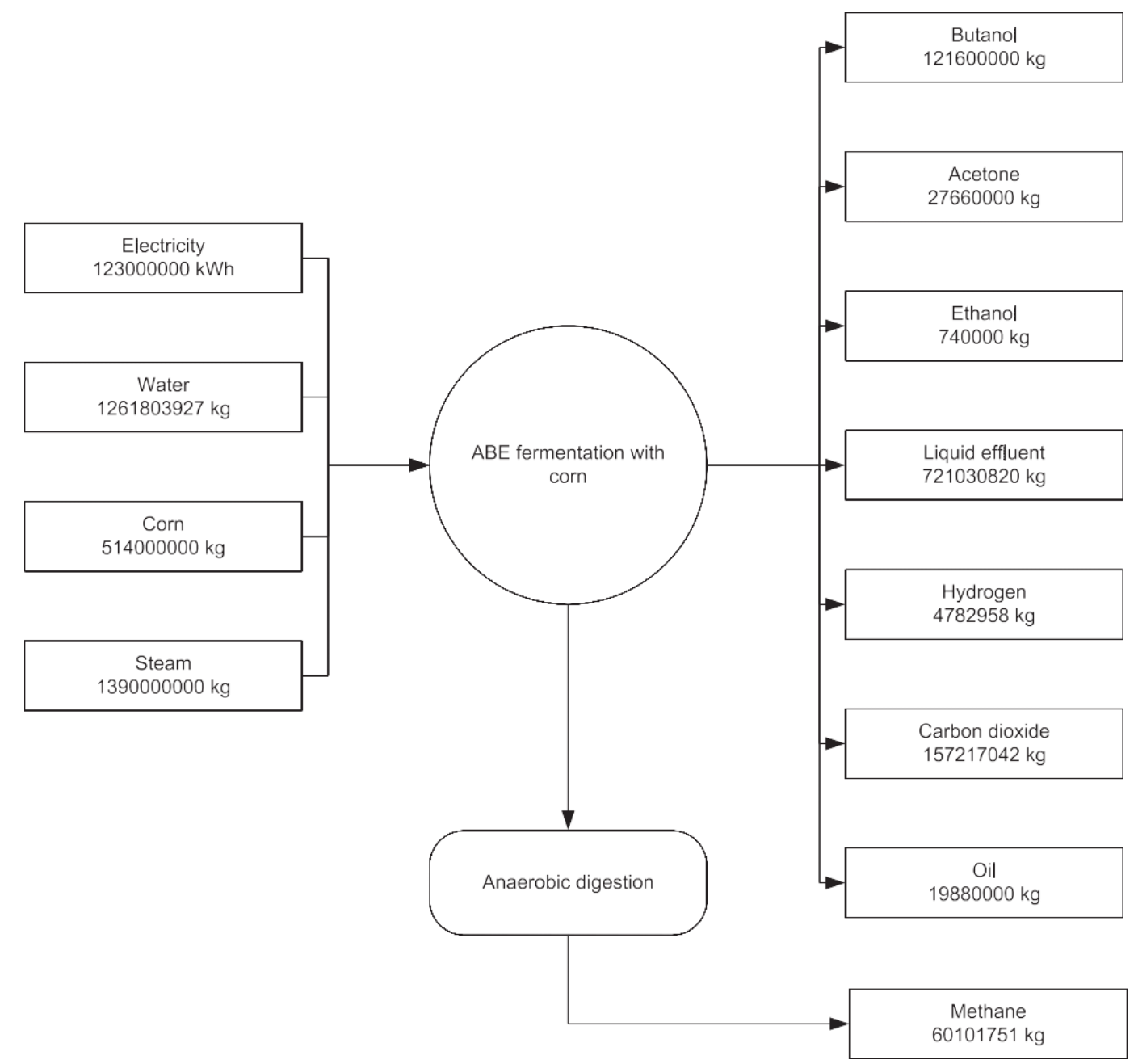

Fig. 5. Inventory ABE process with corn.

Table 1

Allocation methods and ratios.

\begin{tabular}{|c|c|c|c|c|}
\hline & \multicolumn{2}{|c|}{ ABE process with wheat straw (\%) } & \multicolumn{2}{|c|}{ ABE process with corn (\%) } \\
\hline & Mass ratio & Economic ratio & Mass ratio & Economic ratio \\
\hline n-butanol & 19.82 & 44.34 & 31.02 & 49.31 \\
\hline Acetone & 10.48 & 19.95 & 7.06 & 9.54 \\
\hline Ethanol & 3.83 & 3.65 & 0.19 & 0.13 \\
\hline Gases & 56.29 & 22.89 & 41.33 & 11.94 \\
\hline Methane & 9.58 & 9.17 & 15.33 & 10.43 \\
\hline Oil & - & - & 5.07 & 18.65 \\
\hline
\end{tabular}

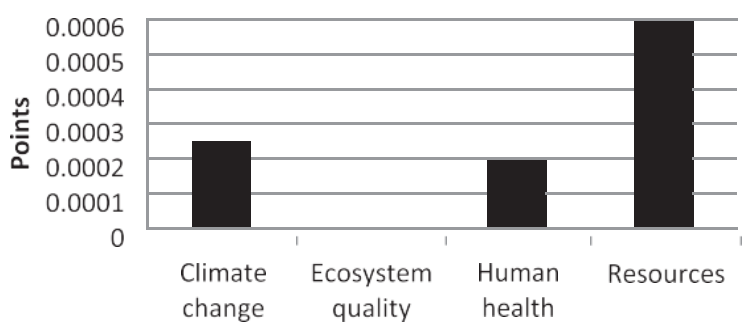

Fig. 6. Environmental impacts for production of $1 \mathrm{~kg}$ of butanol - oxo process.

\section{Sensitivity analysis}

A sensitivity analysis was performed for the production of butanol from the two ABE processes using mass allocation. To perform this analysis data of lower quality were vary to see how this would affect the environmental impacts. In the ABE process using wheat straw the mass of gases produced, the amount of materials sent for the anaerobic digestion and the amount of wastewater produced were reduced and in the ABE process using corn only the amount of wastewater produced was reduced. For the former process a design experiment was considered since it maximizes the amount of information obtained with a minimum of simulations [43]. In this design three factors (mass of gases produced, the amount of materials sent for the anaerobic digestion and the amount of wastewater produced) and two levels (two values) were used. The higher level $(+1)$ for each factor is the value presented in Fig. 4, the lower level (-1) corresponds to a reduction of $50 \%$ in the value presented in Fig. 4. The higher value $(+1)$ corresponds according to the estimates to the maximum value so the variations 


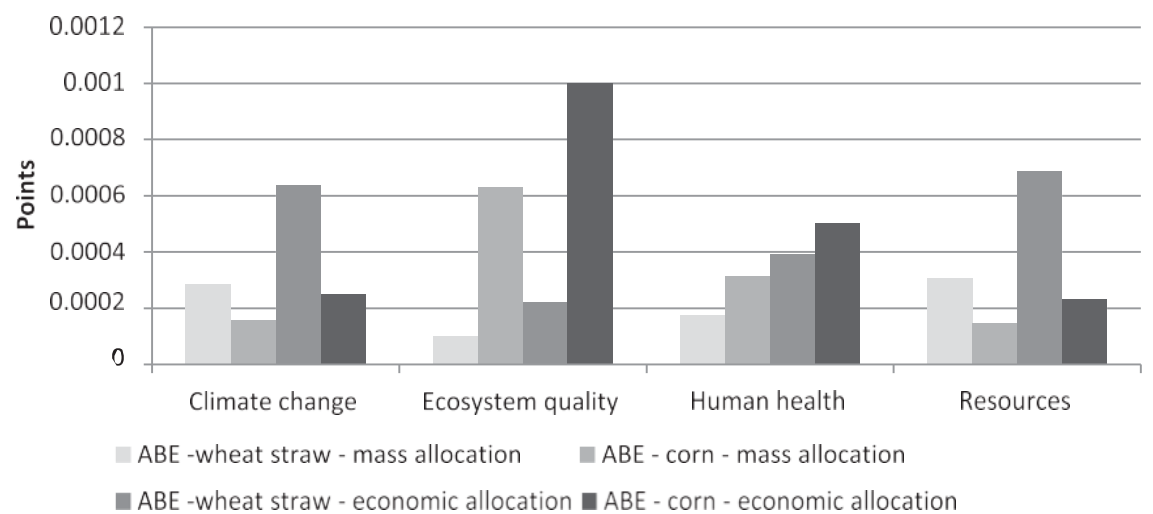

Fig. 7. Environmental impacts for production of $1 \mathrm{~kg}$ of butanol - ABE processes.

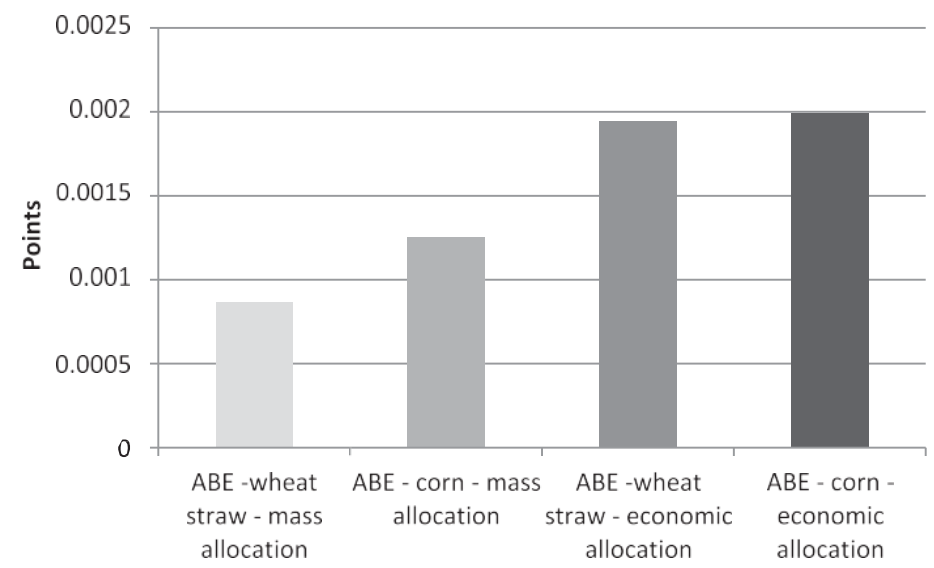

Fig. 8. Total environmental impact for production of $1 \mathrm{~kg}$ of butanol $-\mathrm{ABE}$ processes.

Table 2

Design experiment and environmental impact for $1 \mathrm{~kg}$ butanol.

\begin{tabular}{|c|c|c|c|c|c|}
\hline Scenarios & Production of gases & Wastewater & Materials to $A D$ & Environmental impact (points) & Deviation to baseline (\%) \\
\hline 1 & -1 & -1 & -1 & 0.00123 & 41.3 \\
\hline 2 & 1 & -1 & -1 & 0.00086 & -0.5 \\
\hline 3 & -1 & 1 & -1 & 0.00128 & 47.1 \\
\hline 4 & 1 & 1 & -1 & 0.00090 & 3.6 \\
\hline 5 & -1 & -1 & 1 & 0.00116 & 33.7 \\
\hline 6 & 1 & -1 & 1 & 0.00083 & -3.9 \\
\hline 7 & -1 & 1 & 1 & 0.00121 & 39.2 \\
\hline 8 & 1 & 1 & 1 & 0.00087 & 0.0 \\
\hline
\end{tabular}

are only focused on reductions of the amounts. Table 2 presents the different scenarios studied and the results obtained, including the deviation to baseline scenario (number 8 ) that uses the values presented in Fig. 4.

The variations had no meaningful effect in the global impact $(<4.0 \%)$ except when the production of gases varied. In the scenarios where the mass of gases produced was reduced to $50 \%$ that implied a significant increase in the global impact (roughly $40 \%$ ). For the ABE process with the corn only the amount of wastewater produced was varied and this resulted in a decrease of environmental impact lower than $1 \%$.

\section{Conclusion}

In the quest for alternatives to fossil fuels the butanol production from renewables sources can be a very interesting solution.
However it is important to analyse the economic, environmental and sustainability aspects of solutions found. In this work the environmental impacts of three production processes of $n$-butanol were determined using LCA methodology. The ABE fermentation process using corn as substrate presents the highest environmental impact and the ABE fermentation using wheat straw is the one that presents the lowest environmental impact, when the allocation method was based on mass. When the allocation method is based on the economic values of products obtained the global environmental impact in $A B E$ processes significantly raises due to the lower economic value of gases produced during fermentation.

The sensitivity analysis performed showed that environmental impact is highly affect by the amount of gases produced and they are responsible for the differences registered in global environmental impact when the allocation method changes (mass based or economic based) because of its low economic value. 
The economic viability of $A B E$ processes is highly affected by price of substrates, presence of inhibitors and inefficient recover of products as already mentioned. From a point of view of sustainability the use of corn and other similar substrates can cause some problems in human food supply and increase social impacts.

The use of $n$-butanol as a fuel presents promising potential in the energy systems, namely in the transportation sector and its use can help achieve the EU countries national targets established. It can be a strategic source of renewable energy to replace gasoline and other petroleum products, especially when using subtracts such as straw, because it presents lower social and environmental impacts. From an economic point of view it has the advantage of maintaining the products (straw) within the economy which is in accordance with EU policy of circular economy. Taking in consideration all these factors, n-butanol produced from this kind of subtract is a sustainable solution. However the fermentation process should be further developed to decrease even more the impacts and this implies more investment and the promotion of research in this field.

\section{References}

[1] Directive 2009/28/EC of the European Parliament and of the Council of 23 April 2009 on the Promotion of the Use of Energy from Renewable Sources.

[2] Kitzing L, Mitchell C, Morthorst P. Renewable energy policies in Europe: converging or diverging? Energy Policy 2012;51:192-201.

[3] Dogan E, Seker F. Determinants of $\mathrm{CO}_{2}$ emissions in the European Union: the role of renewable and non-renewable energy. Renewable Energy 2016;94:429-39.

[4] Nicolli F, Vona F. Heterogeneous policies, heterogeneous technologies: the case of renewable energy. Energy Economics 2016;56:190-204.

[5] Dogan E, Seker F. The influence of real output, renewable and non-renewable energy, trade and financial development on carbon emissions in the top renewable. Renew Sustain Energy Rev 2016;60:1074-85.

[6] Dogan E, Turkekul B. $\mathrm{CO}_{2}$ emissions, real output, energy consumption, trade, urbanization and financial development: testing the EKC hypothesis for the USA. Environ Sci Pollut Res 2016;23(2):1203-13.

[7] Dogan E, Seker F. An investigation on the determinants of carbon emissions for OECD countries: empirical evidence from panel models robust to heterogeneity and cross-sectional dependence. Environ Sci Pollut Res 2016:110.

[8] Jebli MB, Youssef SB. Economic growth, combustible renewables and waste consumption, and $\mathrm{CO}_{2}$ emissions in North Africa. Environ Sci Pollut Res 2015;22(20):16022-30.

[9] Al-Mulali U, Ozturk I, Lean $\mathrm{HH}$. The influence of economic growth, urbanization, trade openness, financial development, and renewable energy on pollution in Europe. Nat Hazards 2015;79(1):621-44.

[10] Jebli MB, Youssef SB, Ozturk I. Testing environmental Kuznets curve hypothesis: the role of renewable and non-renewable energy consumption and trade in OECD countries. Ecol Ind 2016;60:824-31.

[11] Shafiei S, Salim RA. Non-renewable and renewable energy consumption and $\mathrm{CO}_{2}$ emissions in OECD countries: a comparative analysis. Energy Policy 2014;66:547-56.

[12] Natalense JC. Prospeção Tecnológica de Biobutanol no Contexto Brasileiro de Biocombustíveis. Universidade de São Paulo; 2013.

[13] Liu H, Wang G, Zhang J. The Promising Fuel-Biobtunol, 2013 [Chapter 6].

[14] Van der Merwe AB, Cheng H, Görgens JF, Knoetze JH. Comparison of energy efficiency and economics of process designs for biobutanol production from sugarcane molasses. Fuel 2013;105:451-8.

[15] U.S. Department of Energy's Clean Cities Program. Alternative Fuels Data Center: Biobutanol. Alternative Fuels Data Center [Online]. Available: http:// www.afdc.energy.gov/fuels/emerging_biobutanol.html; 2015 [accessed 18.02.15].

[16] García V, Pakkila J, Ojamo H, Muurinen E, Keiski R. Challenges in biobutanol production: how to improve the efficiency? Renewable Sustainable Energy Rev 2011;15:964-80.

[17] Liu K, Atiyeh HK, Pardo-Planas O. Process development for biological production of butanol from Eastern redcedar. Bioresour Technol 2015;176:88-97.
[18] Wu M, Wang M, Liu J, Huo H. Life-Cycle Assessment of Corn-Based Butanol as a Potential Transportation Fuel. Argonne National Laboratory; 2007.

[19] Ezeji TC, Qureshi N, Blascheka HP. Continuous butanol fermentation and feed starch retrogradation: butanol fermentation sustainability using Clostridium beijerinckii BA10. J Biotechnol 2005;115:179-87.

[20] Uyttebroek M, Van Hecke W, Vanbroekhoven K. Sustainability metrics of 1 butanol. Catal Today 2015;239:7-10.

[21] Gallardo R, Alves M, Rodrigues LR. Modulation of crude glycerol fermentation by Clostridium pasteurianum DSM 525 towards the production of butanol. Biomass Bioenergy 2014;71:134-43.

[22] Moon C, Lee $\mathrm{CH}$, Sang B, Um Y. Optimization of medium compositions favoring butanol and 1,3-propanediol production from glycerol by Clostridium pasteurianum. Bioresour Technol 2011

[23] Ndaba B, Chiyanzu I, Marx S. N-Butanol derived from biochemical and chemical routes: a review. Biotechnol Reports 2015;8:1-9.

[24] Schiel-Bengelsdorf B, Linder S, Durre P. Butanol fermentation. Environ Technol 2013;34(13-14):1691-710.

[25] Bellido C, Pinto ML, Coca M, González-Benito G, García-Cubero MT. Acetonebutanol-ethanol (ABE) production by Clostridium beijerinckii from wheat straw hydrolysates: efficient use of penta and hexa Carbohydrates. Bioresour Technol 2014;167:198-205.

[26] Dolejš I, Krasnan Krasnan, Stlouka R, Rosenberg M, Rebroš M. Butanol production by immobilised Clostridium acetobutylicum in repeated batch, fed-batch, and continuous modes of fermentation. Bioresour Technol 2014;169:723-30.

[27] Sukumaran RK, Gottumukkala LD, Rajasree K, Alex D, Pandey A. Butanol fuel from biomass: revisiting ABE fermentation. Biofuels 2011;25:571-86.

[28] Zheng J, Tashiro Y, Wang Q, Sonomoto K. Recent advances to improve fermentative butanol production: genetic engineering and fermentation technology. J Biosci Bioeng 2015;119(1):1-9.

[29] Cai D, Chen H, Chen C, Hu S, Wang Y, Chang Z, et al. Gas strippingpervaporation hybrid process for energy-saving product recovery from acetone-butanol-ethanol (ABE) fermentation broth. Chem Eng J 2016;287:110.

[30] Wang L, Chen $\mathrm{H}$. Increased fermentability of enzymatically hydrolyzed steamexploded corn stover for butanol production by removal of fermentation inhibitors. Process Biochem 2011;46:604-97.

[31] Kumar M, Goyal Y, Sarkar A, Gayen K. Comparative economic assessment of ABE fermentation based on cellulosic and non-cellulosic feedstocks. App Energy 2012;93:193-204.

[32] Mohammed F, Biswas WK, Yao H, Tad M. Identification of an environmentally friendly symbiotic process for the reuse of industrial byproduct - an LCA perspective. J Clean Prod 2016;112:3376-87.

[33] Varanda M, Pinto G, Martins F. Life cycle analysis of biodiesel production. Fue Process Technol 2011;92(5):1087-94

[34] Ecoivent 3.2; 2015.

[35] Qureshi N, Saha BC, Cotta MA, Singh V. An economic evaluation of biological conversion of wheat straw to butanol: a biofuel. Energy Convers Manage 2013;65:456-62

[36] Qureshi N, Blaschek HP. Economics of butanol fermentation using hyperbutanol producing Clostridium beijerinckii BA101. Trans IChemE 2000;78C:139-44.

[37] Mariano AP, Dias MOS, Junqueira TL, Cunha MP, Bonomi A, Filho RM Utilization of pentoses from sugarcane biomass: techno-economics of biogas vs. butanol production. Bioresour Technol 2013;142:390-9.

[38] Mariano AP, Dias MOS, Junqueira TL, Cunha MP, Bonomi A, Filho RM. Butano production in a first-generation Brazilian sugarcane biorefinery: technical aspects and economics of greenfield projects. Bioresour Technol 2013;135:316-23.

[39] Qureshi N, Singh V, Liu S, Ezeji TC, Saha BC, Cotta MA. Process integration for simultaneous saccharification, fermentation, and recovery (SSFR): production of butanol from corn stover using Clostridium beijerinckii P260. Bioresour Technol 2014;154:222-8.

[40] Greene C. Organic Agriculture, USDA Economic Research Service, 2015 [Online]. Available: http://www.ers.usda.gov/topics/natural-resourcesenvironment/organic-agriculture.aspx; 2015. [accessed 01.10.15].

[41] Zverlov VV, Berezina O, Velikodvorskaya GA, Schwarz WH. Bacterial acetone and butanol production by industrial fermentation in the Soviet Union: use of hydrolyzed agricultural waste for biorefinery. Appl Microbiol Biotechnol 2006;71(5):587-97.

[42] Raman S, Mohr A, Helliwell R, Ribeiro B, Shortall O, Smith R, et al. Integrating social and value dimensions into sustainability assessment of lignocellulosic biofuels. Biomass Bioenergy 2015;82:49-62.

[43] Montgomery DC. Design and Analysis of Experiments. John Wiley \& Sons Inc.; 2005 